\title{
Perfil de violência sexual em mulheres: uma revisão integrativa da literatura
}

\section{Profile of sexual violence in women: an integrative literature review}

\author{
Letícia Sousa do Nascimento' • Isabelle Guerreiro de Oliveira ${ }^{2} \bullet$ Thays Queiroz Santos ${ }^{2}$ \\ Nébia Maria Almeida de Figueiredo ${ }^{3}$ Tania de Sousa Pinheiro Medeiros $^{4} \bullet$ Claudio Joaquim Borba-Pinheiro $^{5}$
}

\begin{abstract}
RESUMO
Objetivo: Caracterizar os casos de violência sexual nas mulheres, em nível mundial, no período de 2015 a 2019. Método: Foi realizada uma revisão integrativa da literatura, com informações consultadas nas bases de dados do PubMed/Medline, SciELO, Lilacs e Google Acadêmico. Os descritores escolhidos para o método de busca foram: Delitos; Sexuais; Epidemiologia;Violência, nos seguintes idiomas: inglês, português e espanhol. Resultados: Categorizou-se a prevalência dos conteúdos sobre a predominância da Violência Sexual nos seguintes eixos: I- predominância em indivíduos do sexo feminino, n=2; 2- no período da infância e adolescência $n=4$; 3 - perpetrados sujeitos do sexo masculino e/ou da família, $n=I$; 4- dificuldades enfrentadas por profissionais a fim de prestar assistência a essas vítimas, $n=I$. Conclusão: Notou-se que a violência sexual em mulheres ocorre, principalmente, por questões socioculturais e de gênero da vítima e agressor; resultando em consequências a curto e longo prazo, como lesões corporais, danos emocionais e psicológicos. Todavia, há ainda a ocorrência de violência sexual em pessoas do sexo masculino, mas em escala reduzida, por motivos de constrangimento, medo de denunciar, confusão e tabus impostos pela sociedade.
\end{abstract}

Descritores: Delitos Sexuais; Identidade de Gênero;Violência; Saúde Pública.

\begin{abstract}
Objective:To characterize cases of sexual violence in women, worldwide, in the period from 2015 to 20I9. Method:An integrative literature review was conducted, with information consulted in the databases of PubMed / Medline, SciELO, Lilacs and Google Scholar.The descriptors chosen for the search method were: Offenses; Sexual; Epidemiology;Violence, in the following languages: English, Portuguese and Spanish. Results:The prevalence of content was categorized on the prevalence of Sexual Violence in the following axes: I- predominance in females, $n=2 ; 2$ - in the period of childhood and adolescence $n=4 ; 3$ - male and/or family subjects perpetrated, $n=1 ; 4$ - difficulties faced by professionals in order to provide assistance to these victims, $n$ $=\mathrm{I}$. Conclusion: It was noted that sexual violence in women occurs, mainly, due to sociocultural and gender issues of the victim and aggressor; resulting in short and long-term consequences, such as bodily injury, emotional and psychological damage. However, there is still the occurrence of sexual violence in male people, but on a small scale, for reasons of embarrassment, fear of denouncing, confusion and taboos imposed by society.

Keywords: Sex Offense; Genre Identity;Violence; Public Health.
\end{abstract}

I. Discente do curso de enfermagem da Universidade do Estado do Pará, Campus Tucuruí-PA, Brasil. Bolsista do Programa Institucional de Bolsas de Iniciação Científica (PIBIC/CNPQ). E-mail: leticiasnascimentol819@gmail.com.

2. Discente do curso de enfermagem da Universidade do Estado do Pará, Campus Tucuruí-PA, Brasil.

3. Docente do PPGENfBIO da UNIRIO, Rio de Janeiro-RJ, Brasil.

4. Enfermeira. Especialista em Enfermagem Pediátrica/Neonatal/Obstétrica/Ginecológica. Docente do curso de enfermagem da Universidade do Estado do Pará, Campus Tucuruí-PA, Brasil.

5. Docente curso de Educação Física da Universidade do Estado do Pará, Campus Tucuruí-PA e Instituto Federal do Pará, Campus de Tucuruí-PA, Brasil. 


\section{INTRODUÇÃO}

A violência sexual está inserida em uma realidade histórica e social, alicerçada em uma cultura baseada no patriarcalismo, atingindo indivíduos de todas as idades, classes e gêneros. Os dados da United Nations Entity for Gender Equality and the Empowerment of Women, demonstraram que $35 \%$ a $70 \%$ das mulheres foram alvo de violência física e/ou sexual em algum momento, contudo esse problema ainda é de difícil notificação, já que boa parte das vítimas possuem um sistema de apoio social insuficiente, além de se preocuparem com retaliações e descrédito(').

O ato sexual envolve não só a conjunção carnal (penetração do pênis na vagina), com ou sem consentimento, como também atos libidinosos, os quais são práticas que possuem a finalidade de obter prazer sexual (incluindo penetração anal, masturbação, sexo oral, entre outros) $)^{(2-3)}$.

Vale ressaltar que a legislação brasileira destaca violência sexual como qualquer ato que obrigue a observar, manter ou colaborar com práticas sexuais sem consentimento, por meio da força, aterrorização, imposição ou coerção; induzir a vender ou usar, de qualquer forma, sua sexualidade; que proíba a utilização de qualquer contracepção; forçar o matrimônio, à gravidez, o aborto ou à prostituição, através de extorsão, aliciamento ou manipulação; cancelar o exercício dos direitos sexuais e reprodutivos $^{(4)}$.

A violência sexual existe também quando a pessoa não se encontra em condições consentir, em casos de embriaguez e outras drogas, dormindo ou mentalmente inapta. Mas ainda, inclui: o estupro dentro ou fora de um relacionamento, tentativas sexuais não desejadas ou assédio sexual que podem ocorrer em qualquer ambiente, violação sistemática e outros métodos de violência, especificamente comuns em casos de conflito armado, abuso de pessoas com incapacidades físicas ou psicológicas, estupro e abuso sexual de crianças e meios "tradicionais" de violência sexual ${ }^{(5)}$.

Ademais, a violência sexual possui consequências devastadoras nas áreas físicas e mentais, a curto e longo prazo, como a gravidez, patologias no trato reprodutivo, infecções sexualmente transmissíveis (IST), perturbações ginecológicas e sexuais. Indivíduos com histórico de violência sexual possui maior propensão para sintomas psiquiátricos, sobretudo depressão, suicídio, abuso, pânico e dependência química ${ }^{(6)}$.

Tal situação representa um sério problema de saúde pública, já que é tido como um dos principais motivos de morbidade, sobretudo com o sexo feminino. Assim, é imprescindível reconhecer os serviços de saúde como portas de entrada essenciais aos indivíduos que passaram por violência sexual. Para que isso aconteça de fato, é necessário que a população tenha ciência das demandas de serviços e seja encorajada a procurá-los ${ }^{(7)}$. Diante disso, a questão norteadora deste estudo se apresenta da seguinte forma: qual o perfil da Violência Sexual nas mulheres, no período de 2015 a 2019?

Logo, o objetivo da pesquisa é caracterizar os casos de violência sexual nas mulheres, em nível mundial, através de uma revisão integrativa da literatura, no período de 2015 a 2019.

\section{MÉTODOS}

O estudo trata-se de uma revisão bibliográfica do tipo integrativa, que consiste na avaliação de pesquisas importantes para a prática clínica, permitindo o destaque de pontos positivos, negativos, evolução e probabilidades sobre determinado assunto, através de cinco etapas para sua construção( ${ }^{(8)}$.

Para a construção da pesquisa, utilizou-se os seguintes passos: I- elaboração da pergunta da pesquisa; 2- busca na literatura; 3- coleta de dados; 4- análise criteriosa dos artigos incluídos; 5- discussão dos resultados e 6apresentação da revisão integrativa de acordo com o que recomenda o Grupo Ănima Educação(9).

As informações foram consultadas nas bases de dados PubMed/Medline (National Library of Medicine and National Institutes of Health), biblioteca virtual SciELO, Lilacs e Google Acadêmico. Os descritores escolhidos para o método de busca - todos presentes nos Descritores em Ciências da Saúde (DeCS/Bireme) e Medical Subject Headings (MeSH/PubMed) -, que se adaptam melhor a questão norteadora são: Delitos (Offenses); Sexuais (Sex); Epidemiologia (Epidemiology); Violência (Violence). A mesclagem desses descritores foi realizada na língua portuguesa e inglesa, articulados pelo operador booleano "AND".

Os critérios de inclusão foram: artigos de pesquisas, revisões sistemáticas e integrativas da literatura, redigidos e executados nas línguas portuguesa, inglesa e espanhola, no período de 2015 a 2019 , no intuito de delimitar um espaço temporal mais atual possível, com resumo disponível.

Os critérios de exclusão considerados foram editoriais, dissertações, relatos de experiência, teses, monografias, resenhas, produções científicas que demonstravam somente o resumo, estudo de caso e estudos que não tratassem essencialmente da Violência Sexual, no período proposto. Foram descartadas também pesquisas duplicadas, sendo mantidas exclusivamente a primeira versão detectada, e artigos publicados dentro do período proposto, com sua construção precedendo a este momento.

Após a busca dos descritores relacionados com os operadores booleanos e aplicação dos critérios de in- 
clusão e exclusão, foi possível obter um total de 69.098 artigos envolvendo todos os bancos de dados. Em seguida, houve o refinamento de todos os documentos, como evidencia a Figura I além da pré-seleção dos estudos (Quadro I). A avaliação final dos arquivos ocorreu por meio da leitura completa dos artigos pré-selecionados, sendo descartado aqueles que não correspondem ao norteamento do estudo (Quadro I).

Ainda sobre o processo de seleção, o Quadro I apresenta os documentos pré-selecionados para leitura, e consequentemente, inclusão ou descarte definitivos para a composição final dos resultados.

\section{Artigos detectados utilizando os descritores: Delitos (Offenses); Sexuais (Sex); Epidemiologia (Epidemiology); Violência (Violence). Interligados pelo operador booleano "AND"}

Aplicação dos critérios de inclusão e exclusão (avaliação dos títulos e resumos)

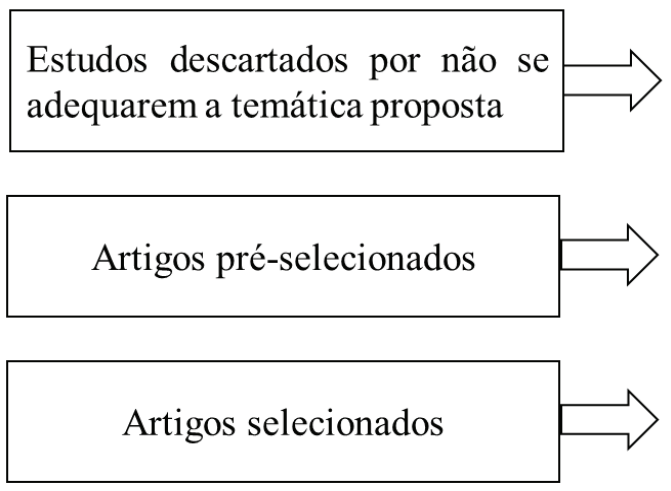

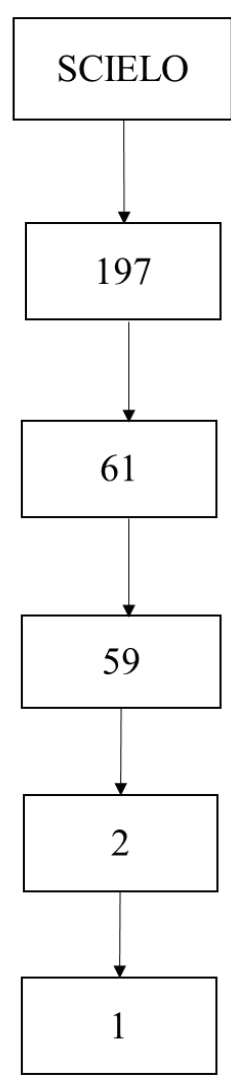
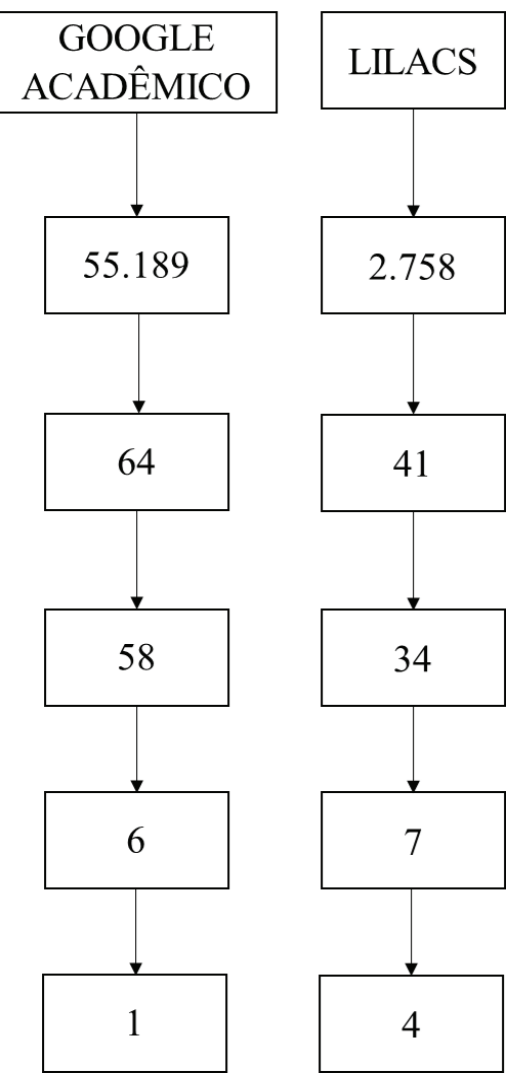

FIGURA 1 - fluxograma da seleção de estudos que melhor se adequam a temática. Tucuruí-PA, Brasil, 2019.

QUADRO 1 - Pesquisas pré-selecionadas. Tucuruí-PA, Brasil, 2019.

\begin{tabular}{|c|c|c|c|}
\hline Artigo & Base & Incluso & Justificativa \\
\hline $\begin{array}{l}\text { Estupros no Brasil e relações com o consumo de álcool: estimativas } \\
\text { baseadas em autorrelato sigiloso }\end{array}$ & Scielo & Não & $\begin{array}{c}\text { Não satisfaz os } \\
\text { objetivos da pesquisa }\end{array}$ \\
\hline $\begin{array}{l}\text { Gender and generation perspectives in the narratives of sexually abused } \\
\text { women in childhood }\end{array}$ & Scielo & Sim & $\begin{array}{l}\text { Se adequa ao } \\
\text { assunto da pesquisa }\end{array}$ \\
\hline Sexual Violence in Adolescents & Pubmed/Medline & Não & $\begin{array}{c}\text { O conteúdo não se } \\
\text { adequa aos objetivos } \\
\text { da pesquisa }\end{array}$ \\
\hline $\begin{array}{c}\text { Awareness of the offense and perception of the victim among juvenile sex } \\
\text { offenders }\end{array}$ & Pubmed/Medline & Sim & $\begin{array}{l}\text { Satisfaz os objetivos } \\
\text { da pesquisa }\end{array}$ \\
\hline $\begin{array}{l}\text { Prevalence of sexual violence and associated factors among primary } \\
\qquad \text { school students - Brazil, } 2015\end{array}$ & Pubmed/Medline & Sim & $\begin{array}{l}\text { Satisfaz os objetivos } \\
\text { da pesquisa }\end{array}$ \\
\hline Social network analysis to characterize women victims of violence & Pubmed/Medline & Não & $\begin{array}{l}\text { Não se adequa ao } \\
\text { objetivo da pesquisa }\end{array}$ \\
\hline $\begin{array}{l}\text { Factors associated with the type of violence perpetrated against } \\
\text { adolescents in the state of Pernambuco, Brazil }\end{array}$ & Pubmed/Medline & Não & $\begin{array}{c}\text { Não aborda o } \\
\text { conteúdo específico } \\
\text { da pesquisa }\end{array}$ \\
\hline Violência sexual na região do ABC Paulista: retrato de 142 casos & Google Acadêmico & Não & $\begin{array}{l}\text { Não se encaixa nos } \\
\text { critérios de inclusão }\end{array}$ \\
\hline $\begin{array}{l}\text { Violência sexual nas relações conjugais e a possibilidade de configurar-se } \\
\text { crime de estupro marital }\end{array}$ & Google Acadêmico & Não & $\begin{array}{c}\text { Não aborta perfil } \\
\text { epidemiológico }\end{array}$ \\
\hline
\end{tabular}




\begin{tabular}{|c|c|c|c|}
\hline $\begin{array}{l}\text { Tráfico sexual de adolescentes e jovens adultos nos Estados Unidos papel } \\
\qquad \text { do profissional de saúde }\end{array}$ & Google Acadêmico & Não & $\begin{array}{l}\text { Não aborta perfil } \\
\text { epidemiológico }\end{array}$ \\
\hline $\begin{array}{l}\text { Estupro contra mulheres brasileiras: características de vítimas e } \\
\text { agressores sexuais }\end{array}$ & Google Acadêmico & Não & $\begin{array}{l}\text { Não se encaixa nos } \\
\text { critérios de inclusão }\end{array}$ \\
\hline $\begin{array}{l}\text { Perfil epidemiológico das menores vítimas de violência } \\
\qquad \text { Sexual em Cuiabá e região }\end{array}$ & Google Acadêmico & Sim & $\begin{array}{l}\text { Satisfaz os objetivos } \\
\text { da pesquisa }\end{array}$ \\
\hline $\begin{array}{l}\text { Identificação e notificação de violência contra crianças e adolescentes: } \\
\text { limites e possibilidades de atuação de profissionais de saúde }\end{array}$ & Google Acadêmico & Não & $\begin{array}{l}\text { Não se encaixa nos } \\
\text { critérios de inclusão }\end{array}$ \\
\hline $\begin{array}{l}\text { Contexto da violência conjugal em tempos de maria da penha: um estudo } \\
\text { em grounded theory / Contexto de la violencia conyugal en tiempos de } \\
\text { maria da penha: estudio en grounded theory / Marital violence context } \\
\text { after the maria da penha law: a grounded theory study }\end{array}$ & Lilacs & Não & $\begin{array}{l}\text { Não aborda } \\
\text { essencialmente o } \\
\text { conteúdo requerido }\end{array}$ \\
\hline $\begin{array}{l}\text { Regulação emocional, satisfação sexual e comportamento sexual de risco } \\
\text { em mulheres vítimas de abuso sexual na infância / Emotion regulation, } \\
\text { sexual satisfaction and risky sexual behavior in women victims of sexual } \\
\text { abuse in childhood }\end{array}$ & Lilacs & Sim & $\begin{array}{l}\text { Em conformidade } \\
\text { com objetivos do } \\
\text { estudo }\end{array}$ \\
\hline $\begin{array}{c}\text { Abordagem a mulheres em situação de violência sexual na perspectiva } \\
\text { da bioética / Atención a mujeres en situación de violencia sexual desde la } \\
\text { perspectiva de la bioética / Attention to women in the situation of sexual } \\
\text { violence in the bioethics perspective }\end{array}$ & Lilacs & Sim & $\begin{array}{c}\text { Material adequado a } \\
\text { pesquisa }\end{array}$ \\
\hline $\begin{array}{c}\text { Violencia sexual: conocimientos y actitudes en adolescentes / Sexual } \\
\text { Violence: Knowledges and attitudes in adolescentes }\end{array}$ & Lilacs & Não & $\begin{array}{l}\text { Não satisfaz os } \\
\text { objetivos da pesquisa }\end{array}$ \\
\hline $\begin{array}{l}\text { Abuso sexual y otras formas de violencia en estudiantes de nivel medio en } \\
\text { el departamento de alto Paraná / Sexual abuse and other types of violence } \\
\text { in high schoolstudents from the department of alto Parana }\end{array}$ & Lilacs & Sim & $\begin{array}{c}\text { Adequado aos } \\
\text { critérios de inclusão }\end{array}$ \\
\hline $\begin{array}{l}\text { Direitos sexuais e reprodutivos de mulheres em situação de violência } \\
\text { sexual: o que dizem gestores, profissionais e usuárias dos serviços de } \\
\text { referência? / Sexual and reproductive rights of women in a sexual violence } \\
\text { situation: what do the managers, professionals and users of reference } \\
\text { services say? }\end{array}$ & Lilacs & Não & $\begin{array}{l}\text { Não aborda } \\
\text { essencialmente o } \\
\text { tema exposto }\end{array}$ \\
\hline $\begin{array}{l}\text { Perfil epidemiológico, clínico-psiquiátrico y legal del sentenciado por } \\
\text { delitos sexuales, Establecimiento Penitenciario Lurigancho, Lima, } 2017\end{array}$ & Lilacs & Sim & $\begin{array}{l}\text { Adequado aos } \\
\text { critérios de inclusão }\end{array}$ \\
\hline
\end{tabular}

\section{RESULTADOS}

Os resultados da seleção dos artigos que atenderam a todos os critérios estão mostrados no (Quadro 2), onde houve, a produção de uma síntese dos artigos selecionados mediante a criação do quadro sinóptico (Quadro I), com destaques essenciais e relevantes das pesquisas selecionadas, a fim de alcançar o objetivo proposto.

Houve um total de oito estudos elencados que ocorreram no período de 2015 a 2019 , tendo como predominância o ano de $2018 \mathrm{com} 75,0 \%(n=6)$. Além disso, $62,5 \%(n=5)$ das pesquisas eram oriundas do Brasil e $37,5 \%(n=3)$ do Paraguai, Peru e Itália.

Quanto aos bancos de dados, 50,0\% $(n=4)$ dos arquivos pertenciam ao Lilacs, 25,0\% $(n=2)$ ao PubMed/ Medline, $12,5 \%(n=1)$ a Scielo e $12,5 \%(n=1)$ ao Google Acadêmico. Já o principal método utilizado entre as pesquisas foi o Descritivo, com 62,5\% $(n=5)$.

Os artigos selecionados foram analisados segundo a metodologia adotada, o que facilitou a identificação, comparação e observação dos padrões entre os dados coletados, conduzindo a um agrupamento de quadro categorias essenciais.

\section{DISCUSSÃO}

Para a produção do conhecimento, há a necessidade de realizar o agrupamento e atualizações de estudos, utilizando a literatura como importante instrumento de resposta as questões levantadas por diferentes públi$\cos ^{(10)}$. A construção da revisão integrativa possibilitou identificar diversas vertentes propostas por pesquisadores a respeito do objeto de estudo em foco - a violência sexual em mulheres. Desse modo, considerou-se não só os aspectos metodológicos das pesquisas selecionadas, como também seus propósitos, para, posteriormente, agrupa-las segundo a correlação entre conteúdo.

Dessa forma, foi possível categorizar a prevalência dos conteúdos sobre a predominância da Violência Sexual nos seguintes eixos: I- predominância em indivíduos do sexo feminino $n=2$, 2- no período da infância e adolescência $n=4,3$ - perpetrados sujeitos do sexo masculino 
QUADRO 2 - síntese dos artigos escolhidos. Tucuruí-PA, Brasil, 2019.

\begin{tabular}{|c|c|c|c|c|c|c|}
\hline $\mathrm{N}^{\circ}$ & Autores (ano) & Título do artigo & $\begin{array}{l}\text { Base de } \\
\text { dados }\end{array}$ & Objetivo & $\begin{array}{c}\text { Delineamento do } \\
\text { estudo }\end{array}$ & $\begin{array}{l}\text { Principais } \\
\text { Resultados }\end{array}$ \\
\hline 1 & $\begin{array}{l}\text { Fornari et al. } \\
\qquad(2018)\end{array}$ & $\begin{array}{l}\text { Gender and } \\
\text { generation } \\
\text { perspectives in the } \\
\text { narratives of sexually } \\
\text { abused women in } \\
\text { childhood. }\end{array}$ & Scielo & $\begin{array}{c}\text { Analisar as } \\
\text { narrativas de } \\
\text { mulheres abusadas } \\
\text { sexualmente na } \\
\text { infância identificando } \\
\text { questões } \\
\text { relacionadas ao } \\
\text { gênero e à geração }\end{array}$ & Revisão Integrativa & $\begin{array}{l}\text { As meninas foram as } \\
\text { principais vítimas de } \\
\text { abuso sexual. } \\
\text { Os perpetradores } \\
\text { eram majoritariamente } \\
\text { do sexo masculino e } \\
\text { conhecidos da família }\end{array}$ \\
\hline 2 & $\begin{array}{l}\text { Santos et al. } \\
\qquad(2019)\end{array}$ & $\begin{array}{l}\text { Prevalence of } \\
\text { sexual violence and } \\
\text { associated factors } \\
\text { among primary } \\
\text { school students - } \\
\text { Brazil, } 2015 .\end{array}$ & $\begin{array}{l}\text { Pubmed/ } \\
\text { Medline }\end{array}$ & $\begin{array}{l}\text { Descrever e analisar } \\
\text { os fatores associados } \\
\text { com a violência } \\
\text { sexual (SV) entre } \\
\text { escola primária } \\
\text { estudantes em Brasil. }\end{array}$ & Estudo descritivo & $\begin{array}{l}\text { A prevalência de VS } \\
\text { foi de } 4,0 \% \text {. A VS } \\
\text { entre adolescentes } \\
\text { em idade escolar } \\
\text { esteve associada a } \\
\text { características como: } \\
\text { idade <13 anos; } \\
\text { fêmea; cor da pele } \\
\text { negra; trabalhando; } \\
\text { ser agredido por } \\
\text { membros da família }\end{array}$ \\
\hline 3 & $\begin{array}{c}\text { Grattagliano et } \\
\text { al. (2018) }\end{array}$ & $\begin{array}{c}\text { Awareness of } \\
\text { the offense and } \\
\text { perception of the } \\
\text { victim among juvenile } \\
\text { sex offenders }\end{array}$ & $\begin{array}{l}\text { Pubmed/ } \\
\text { Medline }\end{array}$ & $\begin{array}{l}\text { Descrever dados } \\
\text { de pesquisas com } \\
\text { adolescentes que } \\
\text { cometeram crimes } \\
\text { sexuais, realizadas } \\
\text { na região de Apúlia, } \\
\text { no sul da Itália }\end{array}$ & Estudo descritivo & $\begin{array}{c}\text { Entre a maioria } \\
\text { dos menores } \\
\text { considerados, emergiu } \\
\text { uma consciência } \\
\text { muito pobre do tipo } \\
\text { peculiar de crime } \\
\text { cometido e de suas } \\
\text { consequências } \\
\text { sobre as vítimas e o } \\
\text { contexto social }\end{array}$ \\
\hline 4 & Talon (2018) & $\begin{array}{c}\text { Perfil epidemiológico } \\
\text { das menores vítimas } \\
\text { de violência } \\
\text { Sexual em Cuiabá e } \\
\text { região }\end{array}$ & $\begin{array}{c}\text { Google } \\
\text { Acadêmico }\end{array}$ & $\begin{array}{c}\text { Demonstrar a } \\
\text { realidade dos óbitos } \\
\text { em consequência } \\
\text { do abuso sexual em } \\
\text { crianças no } \\
\text { território da Grande } \\
\text { Cuiabá, Mato Grosso }\end{array}$ & $\begin{array}{l}\text { Estudo descritivo, } \\
\text { transversal }\end{array}$ & $\begin{array}{l}\text { Através da análise de } \\
\text { prontuários crianças } \\
\text { menores de } 14 \text { anos, } \\
\text { vítimas de violência } \\
\text { sexual atendidas no } \\
\text { IML de Cuiabá no } \\
\text { período de janeiro de } \\
2016 \text { a dezembro de } \\
2016 \text { foi constatado } \\
\text { que a maioria das } \\
\text { vítimas foram do } \\
\text { sexo feminino com } \\
\text { idade entre } 10 \text { e } 12 \\
\text { anos }\end{array}$ \\
\hline 5 & $\begin{array}{c}\text { Krindges e } \\
\text { Habigzang } \\
(2018)\end{array}$ & $\begin{array}{c}\text { Regulação } \\
\text { emocional, } \\
\text { satisfação sexual } \\
\text { e comportamento } \\
\text { sexual de risco em } \\
\text { mulheres vítimas } \\
\text { de abuso sexual na } \\
\text { infância }\end{array}$ & Lilacs & $\begin{array}{l}\text { Avaliar mulheres } \\
\text { que sofreram } \\
\text { Abuso Sexual } \\
\text { na Infância para } \\
\text { investigar questões } \\
\text { relacionadas à } \\
\text { regulação emocional, } \\
\text { à satisfação sexual } \\
\text { e ao comportamento } \\
\text { sexual de risco }\end{array}$ & $\begin{array}{l}\text { Estudo misto de } \\
\text { caráter exploratório } \\
\text { e descritivo }\end{array}$ & $\begin{array}{l}\text { Todas as participantes } \\
\text { avaliadas possuíam } \\
\text { dificuldades de } \\
\text { regulação emocional, } \\
\text { em menores ou } \\
\text { maiores níveis. }\end{array}$ \\
\hline
\end{tabular}




\begin{tabular}{|c|c|c|c|c|c|c|}
\hline 6 & $\begin{array}{c}\text { Trentin et al. } \\
\text { (2018) }\end{array}$ & $\begin{array}{c}\text { Abordagem a } \\
\text { mulheres em } \\
\text { situação de violência } \\
\text { Sexual na } \\
\text { perspectiva da } \\
\text { bioética }\end{array}$ & Lilacs & $\begin{array}{l}\text { Investigar como os } \\
\text { profissionais realizam } \\
\text { a abordagem a } \\
\text { mulheres em } \\
\text { situação de } \\
\text { violência sexual, } \\
\text { na perspectiva } \\
\text { da Bioética de } \\
\text { Intervenção }\end{array}$ & $\begin{array}{l}\text { Qualitativo, } \\
\text { exploratório e } \\
\text { analítico }\end{array}$ & $\begin{array}{c}\text { A equipe } \\
\text { multiprofissional } \\
\text { depara-se com } \\
\text { desafios na } \\
\text { abordagem devido } \\
\text { à falta de ambiente } \\
\text { adequado e de } \\
\text { profissionais para } \\
\text { contemplar a } \\
\text { integralidade do } \\
\text { atendimento, assim } \\
\text { como com déficits no } \\
\text { próprio preparo do } \\
\text { profissional. Persiste } \\
\text { a subnotificação dos } \\
\text { casos e a resistência } \\
\text { em atender casos de } \\
\text { violência sexual }\end{array}$ \\
\hline 7 & $\begin{array}{l}\text { Suhurt et al. } \\
\qquad(2015)\end{array}$ & $\begin{array}{l}\text { Abuso sexual y otras } \\
\text { formas de violencia } \\
\text { en estudiantes } \\
\text { de nivel medio en el } \\
\text { departamento de Alto } \\
\text { Paraná }\end{array}$ & Lilacs & $\begin{array}{l}\text { Determinar a } \\
\text { frequência de abuso } \\
\text { sexual e outras } \\
\text { formas de violência } \\
\text { em estudantes de } \\
\text { nível médio Escolas } \\
\text { de ensino médio do } \\
\text { Paraná }\end{array}$ & $\begin{array}{l}\text { Estudo descritivo, } \\
\text { transversal }\end{array}$ & $\begin{array}{c}\text { A porcentagem } \\
\text { significativa de } \\
\text { adolescentes que } \\
\text { foram vítimas de uma } \\
\text { tentativa } \\
\text { de abuso sexual ou } \\
\text { abuso em algum } \\
\text { momento, muitos } \\
\text { deles dentro do círculo } \\
\text { familiar }\end{array}$ \\
\hline 8 & $\begin{array}{c}\text { Sindeev e } \\
\text { Guzmán-Negrón } \\
(2018)\end{array}$ & $\begin{array}{c}\text { Perfil epidemiológico, } \\
\text { clínico-psiquiátrico y } \\
\text { legal del sentenciado } \\
\text { por delitos sexuales, } \\
\text { Establecimiento } \\
\text { Penitenciario } \\
\text { Lurigancho, Lima, } \\
2017\end{array}$ & Lilacs & $\begin{array}{l}\text { Determinar o perfil } \\
\text { epidemiológico, } \\
\text { clínico-psiquiátrico } \\
\text { e jurídico do } \\
\text { preso detido por } \\
\text { crimes sexuais, } \\
\text { Estabelecimento } \\
\text { Prisional Lurigancho } \\
\text { - de homens -, Lima, } \\
2017\end{array}$ & $\begin{array}{l}\text { Observacional, } \\
\text { descritivo, } \\
\text { transversal e } \\
\text { retrospectivo }\end{array}$ & $\begin{array}{l}\text { O perfil do agressor } \\
\text { sexual não possui } \\
\text { características } \\
\text { específicas que } \\
\text { o diferenciam } \\
\text { claramente da } \\
\text { população em geral, } \\
\text { como a presença de } \\
\text { um transtorno mental } \\
\text { característico }\end{array}$ \\
\hline
\end{tabular}

Legenda: VS: violência sexual; IML: Instituto Médico Legal.

e/ou da família, $\mathrm{n}=\mathrm{I}$; 4- dificuldades enfrentadas por profissionais a fim de prestar assistência a essas vítimas, $n=I$.

Os resultados mostraram que existe uma predominância da violência sexual no sexo feminino, o que em certa medida era esperado. $O$ quinto artigo expressa que a idade das mulheres que sofreram a primeira violência sexual foi entre 5 a 9 anos, onde os agressores, todos do sexo masculino, mantinham relação intrafamiliar ou extrafamiliar e nenhum destes respondeu criminalmente ao abuso, já que a revelação sobre a situação foi tida, na maioria dos casos, com descrédito. As vítimas relataram diversas consequências negativas decorrentes da violência - como desregulação emocional, lesões corporais, aversão sexual, hipersexualidade (compulsão por práticas sexuais), interesse sexual precoce, entre outros ${ }^{(11)}$.

Tais dados podem ser relacionados com o primeiro estudo, de Fornari et al. ${ }^{(12)}$, em que 2 I 4 mulheres brasileiras alegaram ser vítimas de violência sexual quando criança, na idade entre quatro e nove anos, praticados por homens com relacionamento intra ou extrafamiliar, nos ambientes domésticos. Além disso, nota-se que os agressores se beneficiam da inocência infantil e de momentos característicos da infância, como brincadeiras, para executarem o abuso sexual, logo muitos indivíduos que sofrem essas situações possuem dificuldades para denunciar e sofrem consequências a longo prazo.

Todavia, apesar de os casos de violência sexual ocorrerem comumente com o sexo feminino, a Constituição Federal de 1988 expressa que ambos os gêneros são iguais diante da lei, em direitos e deveres. A Carta Magna considera ainda, no artigo $4^{\circ}$, inciso II, que o país também é coordenado pela predominância dos direitos 
humanos. Diante disso, a dignidade humana é tida como princípio essencial do Brasil, conforme o artigo $\mathrm{I}^{\circ}$, Inciso

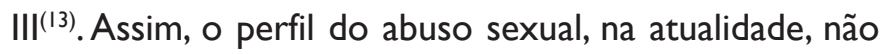
só infringe os direitos humanos, como também revela a desigualdade de gêneros.

Entretanto, através dos métodos de busca e critérios de inclusão e exclusão elencados no trabalho, não foram encontradas pesquisas que evidenciam e discutem, essencialmente, a violência sexual contra o sexo masculino.

Os resultados também mostraram uma predominância da violência sexual na infância e adolescência. No segundo estudo, de Santos et al. ${ }^{(14)}$, os dados revelam que adolescentes do sexo feminino, de cor preta, que não possuíam supervisão de um familiar, apresentavam comportamento de risco (tabagista, etilista, usuário de drogas, mantem relação sexual) e efetuavam trabalho remunerado, demonstraram elevadas chances de sofrerem violência sexual. Contudo, estudar em escolas particulares e ter um responsável com maior grau de escolaridade são fatores protetores.

Ademais, o quarto autor complementa, destacando em seu trabalho que a maior parte das vítimas de violência sexual em menores, são do sexo feminino, com idade menor que 12 anos e possuem consanguinidade com o perpetrador ou relação familiar próxima. Já os agressores, predominantemente do sexo masculino, realizaram atos libidinosos ou conjunções carnais; é válido ressaltar que esses indivíduos utilizam mais ameaças e chantagens para realizar o ato com as vítimas, já que são sujeitos mais fragilizados( ${ }^{(15)}$.

Por conseguinte, quanto a questões sobre violência sexual e idade, crianças e adolescentes são mais vulneráveis a essas agressões, por não saberem como agir, por medo, vergonha, confusão, entre outras causas. E o motivo da predominância pelo sexo feminino envolve diversos fatores culturais e de gênero, os quais submetem as mulheres a situações de abuso e violência. No entanto, os dados de agressão sexual entre adolescentes do sexo masculino podem apresentar-se reduzidos em comparação às meninas, devido a constrangimentos, medo, estereótipos e assim por diante ${ }^{(16)}$.

Além disso, o terceiro artigo destacou uma série de casos que abordam violências praticadas por menores contra outros menores, em que a maior parte dos abusos ocorreram no ambiente extrafamiliar, nas ruas ou escolas, com elevado número de reincidências, sendo executado principalmente por grupos, apresentando como alvo vítimas do sexo feminino, menores de idade. Em geral, os jovens que atacam outros jovens não possuem psicopatologias, e sim alterações sociais, além de que, regularmente, tais agressores deturpam ações provenientes da vítima, por conotações sexuais ${ }^{(17)}$.

Em contrapartida a isso, o sétimo autor, Suhurt et al. (18), afirma que os episódios de tentativa ou execução de abuso sexual ocorreram principalmente com adolescentes, dentro ou próximo do círculo familiar. As demais informações estão em consonância com a pesquisa de Grattagliano et al. ${ }^{(17)}$, pois afirmam que as vítimas são, essencialmente, do sexo feminino, residentes em áreas urbanas, com trabalho remunerado, sendo a maior parte dos agressores, homens, na faixa etária de 16 e 20 anos.

Por conseguinte, o acesso à educação e emprego, são fatores protetores e de enfrentamento contra violências de gênero, já que promovem a autonomia do indivíduo, ocorrendo a redução de, em média, 60 \% da chance de sofrerem abusos sexuais nesses $\operatorname{casos}^{(19)}$.

Além disso, os resultados mostraram ainda a predominância da violência sexual perpetrados por sujeitos do sexo masculino e/ou da família, o que também em alguma medida, era esperado. $O$ perfil de condenados por crimes sexuais, de acordo com a oitava pesquisa selecionada, se apresenta previamente como homens entre 30 a 49 anos, com ensino médio completo, trabalho, relacionamento estável e filhos, usuário de substâncias psicotrópicas, os quais, em sua maioria, cometeram crimes contra a modéstia sexual e/ou estupro, porém não possuem diagnósticos psiquiátricos. Com isso, a violência sexual não deve ser vista somente como algo patológico, e sim, como uma agregação de fatores multicausais do comportamento humano, sendo necessário a implementação de medidas preventivas contra tal situação(20).

Aliado a isso, os dados do Coad $^{(21)}$, revelam que o perfil dos agressores sexuais é indivíduos predominantemente do sexo masculino, entre 30 e 49 anos. Na maior parte das vezes, residem junto a vítima, os quais são padrastos, pais, vizinhos e tios; além disso, a recorrência de casos sobre violência sexual se sobressai, comparado a outras formas de abuso, como a exploração sexual.

Outra questão encontrada nos resultados foram as dificuldades enfrentadas por profissionais a fim de prestar assistência a vítimas de violência sexual. $O$ sexto artigo expressa a existência da responsabilidade profissional, da relação entre servidor-paciente além do âmbito de trabalho, da multidisciplinaridade, a resolutividade no atendimento e a intersetorialidade, no atendimento à mulher violentada sexualmente. Entretanto, ainda há a ausência de compromissos, trabalho em equipe e segurança, por parte de determinados trabalhadores, sendo necessária a educação continuada dos profissionais e a consolidação das políticas públicas, a fim qualificar a assistência a essas vítimas $^{(22)}$.

Em relação a isso, Hasse e Vieira ${ }^{(23)}$, afirmam que as barreiras encontradas por profissionais, para a prestação do cuidado a vítimas de violência sexual, encontram-se na ausência de sensibilização por parte de determinados profissionais de outros setores, durante o acolhimento, a 
existência do preconceito diante da fala das pacientes do sexo feminino, bem como as emoções causadas ante as situações de violência, que refletem, em diversos casos, ocorrências pessoais vivenciadas pelos cuidadores.

Logo, determinados fatores se sobressaem, no intuito de garantir assistência qualificada à mulher vítima de violência sexual, como a articulação efetiva das redes de atendimento, o trabalho em equipe, treinamento e capacitação dos profissionais, implantação de protocolos, infraestrutura e recursos humanos adequados, divulgação dos serviços e facilitação do acesso ${ }^{(24)}$.

Diante do exposto, os resultados da presente pesquisa discutidos com estudos científicos e documentos dos órgãos oficias de saúde, mostram uma necessidade de apoio e sustentação na legislação brasileira vigente, tendo em vista que a violência sexual no Brasil é crime.

Neste sentido, percebe-se que ainda existe uma necessidade da implementação de políticas públicas e ações educativas, a fim de capacitar profissionais e educar a população e a comunidade, sobre o manejo clínico adequado e o acesso a serviços de saúde qualificados para a prestação de assistência às vítimas de violência sexual.

Destaca-se também a existência de leis especificas para o combate contra a violência sexual, ressaltando:

A Lei $n^{\circ}$ 13.43।, de 4 de Abril de 2017, a qual afirma que a violência sexual é considerada qualquer ato que induza a criança e o/ou adolescente a exposição de situações libidinosas, em meios eletrônicos ou presenciais, como abuso sexual (uso do indivíduo para propósitos sexuais, a fim de satisfazer o perpetrador ou terceiros); exploração sexual (utilização do infante em práticas sexuais, para fins lucrativos, de maneira independente ou sob indução) e tráfico de pessoas (é a seleção, transferência e instalação de indivíduos, em um determinado território, para a exploração sexual, através de intimidações e outros métodos de coação) ${ }^{(25)}$.

Essa legislação garante os direitos da criança e do adolescente vítima ou testemunha de violência, elabora formas de prevenção e controle, e determina métodos de atendimento e proteção a esse público. $\bigcirc$ trabalho em conjunto do Estado e sociedade, assegura a execução dessas medidas, onde são levados em consideração as particularidades e casos de cada indivíduo ${ }^{(25)}$.

De acordo com o Estatuto da Criança e do Adolescente, (Lei n.8.069, de I 3 de julho de 1990), a exposição e exploração desse público a qualquer ambiência pornográfica, a prostituição ou outras práticas ilegais envolvendo sexo explícito (registros, vendas, trocas, publicações, armazenamentos, simulações, montagens, coações, assédios ou constrangimentos, por qualquer meio, a fim de induzir a atos libidinosos, entre outros), são considerados crimes, tendo como penalidades reclusões de I a 10 anos, multas e perda de bens, dependendo do delito cometido, onde tal aplicação é facultativa para vítimas entre $\mid 8$ a $2 \mid$ anos $^{(26)}$.

Quanto a violência sexual em adultos, a Lei $n^{\circ} 13.718$, de 24 de setembro de 2018, declara que os crimes de importunação sexual e divulgação de cena de estupro, sexo ou pornografia possuem a penalidade de I a 5 anos, caso a prática não envolva um crime mais grave (aumento da pena, para o ultimo crime, em situações de relação íntima afetiva com a vítima e para fins de vingança ou humilhação) $)^{(3)}$.

Observa-se, também, a possibilidade de elevar a sanção, quando houver: agressor com título de autoridade sobre o indivíduo, consequente gravidez, transmissão de doenças sexualmente transmissíveis, vítima idosa ou deficiente, estupro coletivo e estupro corretivo. Ainda vale destacar que não há ilicitude em divulgações de conteúdos libidinosos, nos ambientes jornalísticos, científicos, culturais e acadêmicos, onde ocultam a identificação da vítima ou tenham autorização sua prévia, se for maior de idade ${ }^{(3)}$.

Além disso, a Lei Maria da Penha (Lei $n^{\circ}$ II.340, de 7 de agosto de 2006), destaca que o atendimento à muIher em casos de violência doméstica e familiar envolve $\circ$ acesso as vantagens resultantes do crescimento científico e tecnológico, compreendendo os serviços de contracepção de emergência, a prevenção das Infecções Sexualmente Transmissíveis (IST) e da Síndrome da Imunodeficiência Adquirida (AIDS), além de outros cuidados médicos essenciais nos casos de violência sexual, incluindo ainda, o ressarcimento dos danos causados a vítima e ao SUS, por parte do agressor ${ }^{(4)}$.

\section{CONCLUSÃO}

A revisão integrativa da literatura demonstra uma noção sobre a caracterização da violência sexual, mediante o panorama sistemático da pesquisa científica de diversos autores. Nas pesquisas selecionadas identificou-se que a predominância de vítimas do abuso sexual se encontra em indivíduos do sexo feminino, onde tais atos ocorrem, predominantemente, na infância e/ou adolescência, devido a questões socioculturais e de gênero da vítima e agressor; resultando em consequências a curto e longo prazo, como lesões corporais, danos emocionais e psicológicos.

Todavia, há ainda a ocorrência de violência sexual em pessoas do sexo masculino, mas em escala reduzida, por motivos de constrangimento, medo de denunciar, confusão e tabus impostos pela sociedade.

Destacou-se também o perfil dos agressores, os quais são, comumente, do sexo masculino, em que os jovens tendem a agredir vítimas de idades semelhantes, já os adultos, praticam, geralmente, a violência em crianças, adolescentes e mulheres do sexo feminino, por serem considerados grupos fragilizados. Os ambientes observados foram tanto o intrafamiliar, quanto extrafamiliar. 


\section{REFERÊNCIAS}

I. Cabral AMG, Buissa ACR, Carnier CC, Miyazaki ET, Gongora, DVN, Lucania ER, et al. Perfil de mulheres vítimas de abuso sexual atendidas em hospital de ensino. Arq. Ciênc. Saúde [Internet]. 2015 Jul/Set [acesso em I5 set 2019]; 22(I):46-52. Disponível em: https://pdfs.semanticscholar. org/c7l c/0e398fef8fcc0cl39d785d5a2b40 I8fe3d5f.pdf.

2. Barros TA. Conjunção carnal e/ou ato libidinoso consentido com menor de 14 anos. Consentimento válido? Faculdade Eduvale de Avaré [Internet]. 2016 [acesso em 25 jan 2020]. Disponível em: http://www.eduvaleavare.com.br/ wp-content/uploads/20 I6/05/ I I conjucao.pdf.

3. Brasil. Lei $n^{\circ} 13.718$, de 24 de setembro de 2018. Altera o Decreto-Lei $n^{\circ} 2.848$, de 7 de dezembro de 1940 (Código Penal), para tipificar os crimes de importunação sexual e de divulgação de cena de estupro, tornar pública incondicionada a natureza da ação penal dos crimes contra a liberdade sexual e dos crimes sexuais contra vulnerável, estabelecer causas de aumento de pena para esses crimes e definir como causas de aumento de pena o estupro coletivo e o estupro corretivo; e revoga dispositivo do Decreto-Lei $n^{\circ}$ 3.688, de 3 de outubro de 194I (Lei das Contravenções Penais). Brasília-DF: Diário Oficial da União; seção I, ano 155, n. 185, 25 set. 2018. p. I-93.

4. Brasil. Lei $n^{\circ}$ II.340, de 7 de agosto de 2006. Cria mecanismos para coibir a violência doméstica e familiar contra a mulher, nos termos do $\S 8^{\circ}$ do art. 226 da Constituição Federal, da Convenção sobre a Eliminação de Todas as Formas de Discriminação contra as Mulheres e da Convenção Interamericana para Prevenir, Punir e Erradicar a Violência contra a Mulher; dispõe sobre a criação dos Juizados de Violência Doméstica e Familiar contra a Mulher; altera o Código de Processo Penal, o Código Penal e a Lei de Execução Penal; e dá outras providências. Brasília-DF: Diário Oficial da União; seção I, ano I63, n. I5I, 08 ago. 2006. p. I-56.

5. OPAS/OMS. Organização Pan-Americana da Saúde. Organização Mundial da Saúde. Neste Dia Laranja, OPAS/OMS aborda violência sexual e suas consequências para as vítimas [Internet]. Brasília: Organização Pan-Americana da Saúde/Organização Mundial da Saúde; 2018 [acesso em 27 set 2019]. Disponível em: https://www.paho.org/bra/index. php?option=com_content $\&$ view=article\&id=5720: nestedia-laranja-opas-oms-aborda-violencia-sexual-e-suas-consequencias-para-as-vitimas\&ltemid $=820$

6. Facuri C, Fernandes AMS, Oliveira KD, Andrade TS, Azevedo RCS. Violência sexual: estudo descritivo sobre as vítimas e o atendimento em um serviço universitário de referência no Estado de São Paulo, Brasil. Cad. Saúde Pública [Internet]. 2013 maio [acesso em I3 out 2019]; 29(5):889-898. Disponível em: http://www.scielo.br/scielo. php?pid=SO $102-3 \mathrm{I} \mid \times 20 \mathrm{I} 3000500008 \&$ script $=$ sci_abstract\&tlng=pt.
7. Brasil. [Constituição (1988)]. Constituição da República Federativa do Brasil: texto constitucional promulgado em 5 de outubro de 1988, com as alterações determinadas pelas Emendas Constitucionais de Revisão nos I a 6/94, pelas Emendas Constitucionais nos I/92 a 85/20I5 e pelo Decreto Legislativo no 186/2008. Brasília: Senado Federal, Coordenação de Edições Técnicas; 2015.

8. Mendes KDS, Silveira RCCP, Galvão CMG. Revisão integrativa: método de pesquisa para a incorporação de evidências na saúde e na enfermagem. Texto contexto - enferm. [Internet]. 2008 [acesso em $27 \mathrm{dez}$ 2019]; I7(4):758-64. Disponível em: https://www.scielo.br/pdf/tce/vI7n4/I8.pdf

9. Grupo anima educação. Manual Revisão Bibliográfica Sistemática Integrativa: a pesquisa baseada em evidências [Internet]. Belo Horizonte: Grupo Anima Educação; 2014 [acesso em 25 nov 2019]. Disponível em: http://biblioteca. cofen.gov.br/wp-content/uploads/2019/06/manual_revisao_bibliografica-sistematica-integrativa.pdf

10. Oliveira LPBA,Santos SMA.An integrative review of drug utilization by the elderly in primary health care. Rev Esc Enferm USP [Internet]. 2016 [citado em 10 jan 2020];50(I): I67-I 79. Disponível em: https://www.scielo.br/scielo.php?script=sci_ arttext\&pid=S0080-623420 I 6000 I $00163 \&$ Ing=en\&tlng=en

I I. Krindges CA, Habigzang LF. Regulação emocional, satisfação sexual e comportamento sexual de risco em mulheres vítimas de abuso sexual na infância. Estud. psicol. (Campinas). [Internet]. 2018 [acesso em $23 \mathrm{dez}$ 2019]; 35(3):321-332. Disponível em: http://dx.doi.org// 0.1590//982-027520/80003000।0

12. Fornari LF, Sakata-So KN, Egry EY, Fonseca RMGS. Gender and generation perspectives in the narratives of sexually abused women in childhood. Rev. Latino-Am. Enfermagem [Internet]. 2018 [acesso em $26 \mathrm{dez} 2019$ ]; 26:e3078. Disponível em: https://doi.org/10.1590/I5 I8-8345.277।.3078.

13. Brasil. Ministério da Saúde. Ministério da Justiça. Secretaria de Políticas para as Mulheres. Norma técnica: atenção humanizada às pessoas em situação de violência sexual com registro de informações e coleta de vestígios [Internet]. led. Brasília: Ministério da Saúde; 20I5b.

14. Santos MJ, Mascarenhas MDM, Malta DC, Lima CM, Silva MMA. Prevalência de violência sexual e fatores associados entre estudantes do ensino fundamental - Brasil, 2015. Cien Saude Colet. [Internet]. 2019 [acesso em 23 dez 2019]; 24(2):535-544. Disponível em: http://dx.doi. org/I0.1590/I4I3-8I232018242.131I2017

15. Talon MSV. Perfil Epidemiológico dos Menores Vítimas de Violência Sexual em Cuiabá e Região. Caderno de Publicações Univag. [Internet]. 2018 [acesso em $12 \mathrm{dez} 2019$ ]; 9:46-52. Disponível em: http://www.periodicos.univag.com. br/index.php/caderno/article/view/ I 2 I |/ 388

16. Lugão KVMSF, Gonçalves GE, Gomes IM, Silva VP, Jacobson LSV, Cardoso CAA. Abuso sexual crônico: estudo de uma série de casos ocorridos na infância e na adolescência. DST - J bras Doenças Sex Transm [Internet]. 2012 [acesso em 
15 out 2019]; 24(3):I79-182. Disponível em: http://www. dst.uff.br/revista24-3-20I2/6-Abuso_sexual_cronico.pdf

17. Grattagliano I, Craig F, Lisi A, Pierri G, Stallone V, Margari L, et al. Awareness of the offense and perception of the victim among juvenile sex offenders. Clin Ter. [Internet]. 2018 [acesso em 24 nov 2019]; 169(4):el55-el64. Disponível em: https://www.ncbi.nlm.nih.gov/pubmed/30I5I548

18. Suhurt CHA, Ruoti M, Orué E, Suhurt CMS. Abuso sexual y otras formas de violencia en estudiantes de nivel medio en el departamento de Alto Paraná. Mem. Inst. Investig. Cienc. Salud. [Internet]. 2015 [acesso em 23 dez 2019]; I3(3):31-38. Disponível em: http://dx.doi.org//0.18004/ Mem.iics/ I 8I2-9528/2015.0 I3(03)3 I-038

19. Puri M, Frost M, Tamang J, Lamichhane P, Shah I. The prevalence and determinants of sexual violence against young married women by husbands in rural Nepal. BMC Res Notes [Internet]. 2012 [acesso em I5 out 2019]; 5:29I. Disponível em: https://www.ncbi.nlm.nih.gov/pubmed/22695085

20. Sindeev A, Guzmán-Negrón E. Perfil Epidemiológico, Clínico-psiquiátrico y Legal Del Sentenciado por Delitos Sexuales, Establecimiento Penitenciario Lurigancho, Lima, 2017. Acta méd. Peru [Internet]. 2018 [acesso em 28 nov 2019]; 35(3). Disponível em: http://www.scielo.org.pe/scielo. php?script=sci_arttext\&pid=SI 728-59| 72018000300005

21. Coad [Internet]. Abuso sexual: levantamento aponta perfil do agressor e da vítima. $201 \mathrm{I}$ [acesso em 2020 jan 08]. Disponível em: http://www.coad.com.br/home/noticias-detalhe/35760/abuso-sexual-levantamento-aponta-perfil-do -agressor-e-da-vitima

22. Trentin D, Vargas MAO, Pires DEP, Hellmann F, Brehmer L,
Leal SC. Abordagem a Mulheres em Situação de Violência Sexual na Perspectiva da Bioética.Acta Bioethica [Internet]. 2018 [acesso em 05 out 2019]; 24(I): I 17-126. Disponível em: https://scielo.conicyt.cl/pdf/abioeth/v24n I//726-569X -abioeth-24-0I-00I I7.pdf

23. Hasse M,Vieira EM. Como os profissionais de saúde atendem mulheres em situação de violência? Uma análise triangulada de dados. Saúde Debate [Internet]. 2014 [acesso em $27 \mathrm{dez}$ 2020]; 38( I 02):482-493. Disponível em: https://www.scielo. br/scielo.php?pid=SO I 03- | I 0420 | $4000300482 \&$ script=sci_abstract\&tlng=pt

24. Trentin D, Vargas MAO, Lino MM, Leal SMC, Ferreira ML, Saioron I. Atendimento a mulheres em situação de violência sexual: revisão integrativa da literatura. Esc. Anna Nery [Internet]. 2019 [acesso em $27 \mathrm{dez} 201$ 9];23(4):e201 80324. Disponível em: https://www.scielo.br/pdf/ean/v23n4/ pt_|4|4-8|45-ean-23-04-e20 I80324.pdf

25. Brasil. Lei $n^{\circ} 13.43$ I, de 4 de abril de 2017. Estabelece o sistema de garantia de direitos da criança e do adolescente vítima ou testemunha de violência e altera a Lei $n^{\circ} 8.069$, de 13 de julho de 1990 (Estatuto da Criança e do Adolescente) Brasília-DF: Diário Oficial da União; seção I, ano I54, n. 66, 05 abr. 20I7. p. I-223.

26. Brasil. Lei $n^{\circ} 8.069$, de 13 de julho de 1990. Dispõe sobre - Estatuto da Criança e do Adolescente e dá outras providências. [Internet]. Brasília-DF: Diário Oficial da União; seção I, ano I28, n. I35, 16 jul. 1990. p. I-80.

Recebido: 2020-08-13

Aceito: 2020-10-26 